\title{
Effect of Rational-Emotive Behavior Intervention on Managing Burnout Symptoms among Postgraduate Students in Public Universities
}

\author{
Chima C. Igbokwe ${ }^{1}$, Nkiru E. Obande-Ogbuinya ${ }^{2}$, Emmanuel K. Nwala ${ }^{4}$, \\ Uchechukwu A. Ezugwu ${ }^{3} \&$ Uchenna C. Ugwu $^{1}$ \\ ${ }^{1}$ Department of Human Kinetics and Health Education, Faculty of Eduucation, University of Nigeria, Nsukka, \\ Enugu State, Nigeria \\ ${ }^{2}$ Physical and Health Education Unit, Science Education Department, Alex Ekwueme Federal University, \\ Ndufu-Alike, Ebonyi State, Nigeria \\ ${ }^{3}$ Department of Medical Rehabilitation, Faculty of Health Science and Technology, University of Nigeria, Enugu \\ Campus, Nigeria \\ ${ }^{4}$ Social Accountability and Governance Advisor, RTI International/ Health Policy Plus Project, Nigeria \\ Correspondence: Uchechukwu A. Ezugwu, Department of Medical Rehabilitation, Faculty of Health Science and \\ Technology, University of Nigeria, Enugu Campus. Tel: 234-803-691-0730. E-mail: \\ uchechukwu.ezugwu@unn.edu.ng
}

Received: April 13, 2020 Accepted: June 4, 2020 Online Published: June 26, 2020

doi:10.5539/gjhs.v12n9p38 URL: https://doi.org/10.5539/gjhs.v12n9p38

\begin{abstract}
Burnout symptom is an emotional and psychological imbalance commonly experienced by students of tertiary institutions. This unhealthy state of existence is capable of undermining the quality of health and academic performances resulting in exhaustion and disengagement. The current study therefore aimed to investigate the effect of rational-emotive behavior intervention -REBI on managing burnout symptoms among postgraduate students in public universities. This research was based on experimental design involving treatment and control groups. Using a purposive sampling technique, 92 study participants were recruited from the public universities in Nigeria from July 2019 and January 2020. The treatment intervention was delivered to only the experimental group with an evidence-based REBI manual. Data collection process was completed using the Oldenburg Burnout Inventory-student version -OLBIS with internal consistency of 0.77 index. The complete data analysis was done using SPSS version 22. The results indicated that no significant difference existed between the participants in the experimental $(23.17 \pm 2.71)$ and control groups $(21.69 \pm 2.80)$ on OLBI-S pretest, $\mathrm{F}=0.147, \mathrm{P}=.738, \mathrm{~h} 2 \mathrm{p}=0.014$, $\mathrm{DR} 2=0.709, \mathrm{SE}=1.52$. Statistically significant difference was found to exist between the participants in the experimental $(11.43 \pm 4.17)$ and control groups $(22.02 \pm 5.66)$ on OLBI-S posttest scores, $\mathrm{F}=2.081, \mathrm{P}=0.041$, $\mathrm{h} 2 \mathrm{p}=0.105, \mathrm{DR} 2=0.706, \mathrm{SE}=1.40$. This study showed that REBI was effective in managing burnout symptoms among postgraduate students in public universities in Nigeria. The REBI is considered very effective in managing diverse emotional and psychological problems existing among students. There is need for enlightenment and massive health education on burnout and prospective ways of managing it.
\end{abstract}

Keywords: burnout symptoms, REBI, experimental design, effect, postgraduate students

\section{Introduction}

Globally, evidence of burnout symptoms among students abounds (Dyrbye et al., 2012; Heinen, Bullinger \& Kocalevent, 2017). Burnout usually results in poor quality of health (Hamaideh, 2011), academic exhaustion and disengagement (Chou, Li, \& Hu, 2014; Abarghouei et al., 2016). It is an emotional and psychological reaction to prolonged stress that is capable of undermining academic performances. Notably, victims of burnout symptoms are more prone to poor academic achievement with little or no interest in school activities (Lin \& Huang, 2014; Popa-Velea et al., 2017). Most often, they find it difficult to seek professional help, and hardly maintain stable emotion (Ogbuanya et al., 2018). Studies had earlier shown that burnout symptoms significantly predicted depression among students (Al-Alawi et al., 2017), with high prevalence of exhaustion and disengagement (Boni et al., 2018). Further finding also revealed that increased level of burnout was related to high stress (Tavolacci $\&$ 
Veber, 2015). The increasing cases of burnout symptoms and reliable ways to manage them among university students particularly the postgraduates have remained a major concern to health experts and professionals. This current research therefore validated the effect of rational-emotive behavior intervention -REBI on managing burnout symptoms in a sample of postgraduate students in public universities. The application of behavior interventions to combat burnout symptoms among students is crucial in promoting health and enhancing academic performances and achievements. From the literature reviewed, there is evidence-based finding that behavior intervention such as the present (REBI) helped in managing burnout symptoms (Ogbuanya et al., 2018). In managing burnout symptoms, the need for teamwork of experts and clients in addressing self-limiting beliefs, and assumptions are prioritized. Self-assumptions often stampede one from reaching the peak of personal and professional development. The REBI is a health promotion programme based on emotional and psychological health principles and philosophies constructively designed to manage burnout symptoms. The intervention assumes that the postgraduate students are willing to adjust in behavior, adopt sound emotional and psychological skills that would improve the quality of life, enhance academic performances and engage in all school activities. The main focus of REBI centers on improving learning, behavior modifications, skill development and acquisition, proffering solutions to health problems as well as setting realistic goals. Specifically, the current study therefore aimed to

1) investigate the effect of REBI on managing burnout symptoms among postgraduate students in public universities.

2) find out the effect of REBI on managing burnout symptoms among postgraduate students in public universities based on socio-demographic variables.

\subsection{Research Questions}

The study was guided by these research questions:

1) What is the effect of REBI on managing burnout symptoms among postgraduate students in public universities?

2) What is the effect of REBI on managing burnout symptoms among postgraduate students in public universities based on socio-demographic variables?

\subsection{Hypotheses.}

1) The effect of REBI has no significant difference on managing burnout symptoms among postgraduate students in the experimental group when compared to those in the non-treatment group.

2) The effect of REBI has no significant difference on pretest and post test scores in managing burnout symptoms among postgraduate students in the experimental group.

\section{Method}

2.1 Design

This research was based on experimental research design involving treatment and non-treatment control groups.

\subsection{Participants and Procedure}

A purposive sampling technique was adopted by the researchers in recruiting the study participants. This process commenced during postgraduate lecture periods in the universities between July 2019 and January 2020. A total of 92 eligible postgraduate students were recruited from public universities and participated in the study. The participants were gotten from 738 proposed sample figures dully assessed for eligibility (see figure 1). One of the criteria for eligibility stipulated that the participant must be postgraduate student in public university and must have manifested burnout symptoms. Also, the person must complete the informed consent form, must be eager to engage in the programme from the first day till the last day and must not attend any other intervention programme relating to managing burnout symptoms during the periods of intervention. A random assignment of the participants to either in the experimental or non-intervention control groups was done by the investigators. Each group (experimental and control) consisted of 46 postgraduate students who met the stipulated eligibility criteria. The treatment intervention was delivered to only the participants in the experimental group for the period of 8 weeks. The REBI program was delivered using REBI manual. No treatment intervention was given to the participants in the control group. However, the study participants in both experimental and control groups participated in the pretest-posttest assessments. There was financial incentive to the study participants for complying in the study. One of the postgraduate lecture halls in the university served as the venue for treatment intervention as was unanimously agreed by the participants and the investigators with each group session lasting 
for two hours long. . The allocation sequence in this study was generated using simple randomization based on scholastic suggestion (Saghaei, 2014). The study participants in the groups responded successfully and returned the outcome measures at various times via: (pretest); and (post test). The REBI manual was compiled in simple and easy-to-understand English language.

\subsection{Ethical Approval}

The ethical consideration for the research was approved by the Committee on Research Ethics of the Enugu State Ministry of Health. This was based on the ethical conditions and principles as stipulated by the Declaration of Helsinki (World Medical Association, 2013). All the participants in this research gave informed consent to participate.

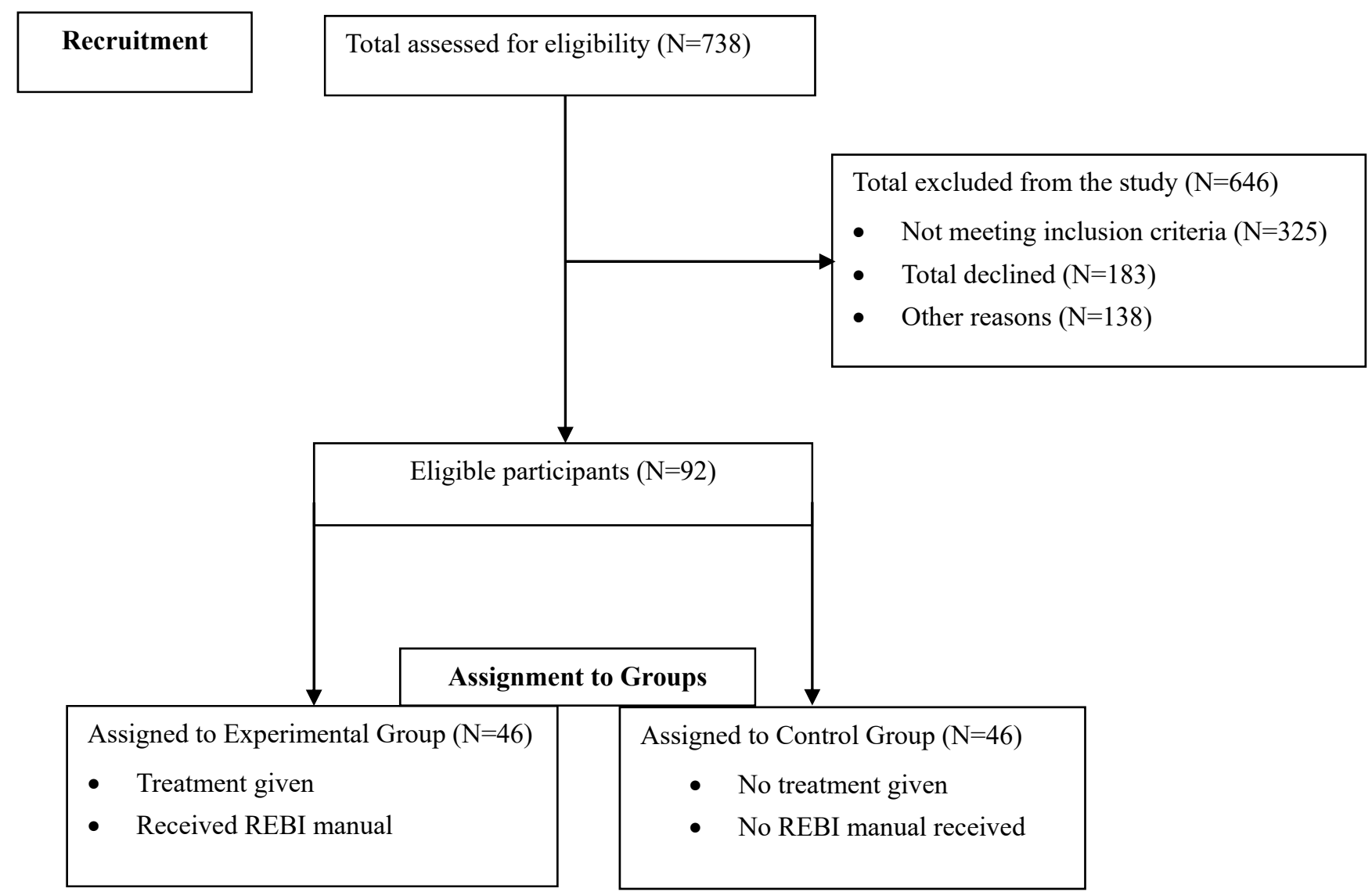

Figure 1. Schema on procedures for the recruitment of study participants (source: authours)

\subsection{Study Instrument}

The data collection process was completed using the Oldenburg Burnout Inventory-Student version -OLBIS (Reis, Xanthopoulou, \& Tsaousis, 2015). The OLBI-S consisted of sixteen item statements rated on a-four point scale of strongly agree -1 , agree -2 , disagree -3 and strongly disagree -4 . Using this scale, it implies that high mean percentage score signifies high level of burnout symptoms while low mean percentage score implies low level of burnout symptoms by the participants. The internal consistency of the OLBI-S as regards to the present study sample was 0.77 . The OLBIS has successfully been applied in similar studies on burnout symptoms and was found to be most appropriate (Campos, Carlotto, \& Marôco, 2012; Reis, Xanthopoulou, \& Tsaousis, 2015). The socio-demographic variables of interest were age, gender and accommodation.

\subsection{Analysis of Data}

The complete data analysis in this study was established using statistical packages for the social science batch system version 22 . The basic statistical assumptions in this study were met, and data were properly cross-checked for completeness. However, no data was found to be missing and all the participants completed the pretest and 
posttest exercises. The findings of the study were considered statistically significant at $\mathrm{P}=0.05$.

\section{Results}

Table 1. Socio-demographic characteristics of the study participants $(\mathrm{N}=92)$

\begin{tabular}{llllll}
\hline \multicolumn{2}{l}{ Characteristics } & Experimental group N (\%) & Control group N (\%) & Statistic & Significance \\
\hline \multirow{2}{*}{ Gender } & Male & $22(48 \%)$ & $25(54 \%)$ & 0.080 & 0.082 \\
& Female & $24(52 \%)$ & $21(46 \%)$ & & 0.613 \\
\hline \multirow{2}{*}{ Age } & Below 25 years & $25(54 \%)$ & $22(48 \%)$ & & 0.032 \\
& 25 years plus & $21(46 \%)$ & $24(52 \%)$ & 1.107 & 0.712 \\
\multirow{2}{*}{ Accom. } & Hostel & $22(48 \%)$ & $25(54 \%)$ & & \\
\hline
\end{tabular}

Keys: $N=$ sample size, $\%=$ percentage, 0 =bracket sign, Accom=accommodation.

A total of 92 postgraduate students participated in the study. Of them, there were $22(48 \%)$ males and $24(52 \%)$ females in the experimental group; and $25(54 \%)$ males and 21 (46\%) female participants in the non-intervention control group, with no statistically significant difference $(0.05<0.082)$. Also, there were $25(54 \%)$ participants below 25 years of age and $21(46 \%)$ of them who were above 25 years in the experimental group; and 22(48\%) of the participants below 25 years and 24(52\%) of them who were above 25 years in the control group, with statistically significant difference $(0.05>0.032)$. Based on accommodation, $22(48 \%)$ participants were hostel occupants and 24 (52\%) were off-campus settlers in the experimental group; and 25 (54\%) hostel-dwellers and 21 (46\%) off-campus occupants in the control group, with no statistically significant difference $(0.05<0.712)$. There was a complete turn-up in attendance by the participants to all the group sessions without any pronounced form of bias, harm or risk (see Table 1).

Table 2. Showing the outcome of REBI on managing burnout symptoms by the study participants ( $\mathrm{N}=92)$

\begin{tabular}{lllllllllll}
\hline Tool & & Period & Group & $\mathrm{M} \pm \mathrm{SD}$ & $\mathrm{SE}$ & $95 \% \mathrm{CI}$ & $\mathrm{F}$ & $\mathrm{Sig}$. & $\mathrm{h} 2 \mathrm{p}$ & DR2 \\
\hline OLBIS & Pre-test & Exptl & $23.17 \pm 2.71$ & 1.52 & $32.51-35$ & .231 & 0.147 & 0.738 & 0.014 & 0.709 \\
Ctrl. & & $21.69 \pm 2.80$ & 1.52 & $32.70-35$ & .432 & & & & & \\
OLBIS & Post-test & Exptl. & $11.43 \pm 4.17$ & 1.40 & $20.161-26$ & .911 & 2.081 & 0.041 & 0.105 & 0.706 \\
Ctrl. & & $22.02 \pm 5.66$ & 1.40 & $18.747-22$ & .387 & & & & & \\
\hline
\end{tabular}

OLBIS=Oldenburg Burnout inventory-student version, DR2=adjusted R2, \%= percentage, h2p=partial eta squared, $\mathrm{CI}=$ confidence interval, mean $\pm \mathrm{SD}=$ mean and standard deviation, $\mathrm{Ctrl}=$ control, $\mathrm{SE}=$ standard error, Exptl=experimental.

The results in Table 2 indicated that no significant difference existed between the participants in the experimental (23.17 \pm 2.71$)$ and control groups $(21.69 \pm 2.80)$ on OLBI-S pretest, $\mathrm{F}=0.147, \mathrm{P}=.738, \mathrm{~h} 2 \mathrm{p}=0.014, \mathrm{DR} 2=0.709$, $\mathrm{SE}=1.52$. The Table also showed that statistically significant difference existed between the participants in the experimental $(11.43 \pm 4.17)$ and control groups $(22.02 \pm 5.66)$ on OLBI-S post test scores, $\mathrm{F}=2.081, \mathrm{P}=0.041$, $\mathrm{h} 2 \mathrm{p}=0.105, \mathrm{DR} 2=0.706, \mathrm{SE}=1.40$. The data further showed that participants in experimental group scored lower $(11.43 \pm 4.17)$ in the posttest when compared to post test scores of those in the control groups $(22.02 \pm 5.66)$. However, there was obvious significant decrease in post test OLBI-S scores when compared with the pretest OLBI-S scores of the study participants in the experimental group. This demonstrated that REBI was effective in managing burnout symptoms among postgraduate students in public universities in Nigeria (see Table 2).

\section{Discussion}

This study investigated the effect of rational-emotive behavior intervention -REBI on managing burnout symptoms among postgraduate students in public universities. The study revealed that REBI was effective in managing burnout symptoms among the study participants in the experimental group when compared to those in 
the control group. It was also revealed that the REBI was effective in managing burnout symptoms when pretest and posttest scores of the participants in the experimental group are compared. This finding demonstrates that REBI is an effective health promoting measure in managing burnout symptoms among postgraduate students in public universities. The finding equally suggests that proper application of REBI can help to manage academic exhaustion and disengagement in students. In line with the observations of other researchers, behavioral intervention such as REBI is an effective tool in enhancing individual and professional growth (Sherin \& Caiger, 2004) as well as cushioning the students to develop skills and abilities to overcome burnout symptoms. Further evidences abound that the successful application of behavior-related interventions successfully reduced burnout symptoms (Ugwoke et al., 2018), managed stress-related symptoms, and alleviated symptoms of burnout syndrome (Ogbuanya et al., 2018). The outcomes of the present study show the significant effect of REBI in managing burnout symptoms in a sample of Nigerian postgraduate students in public universities. The choice of adopting REBI in small sample participants revealed the crucial effect of this intervention on managing burnout symptoms. This research is quiet suggestive. Hence, the university administration should take the responsibility of ensuring that her postgraduate students who are experiencing burnout symptoms benefit from prospective interventions. It is also important that the university authorities consider adopting the REBI for the management of burnout symptoms among students of public universities. This behavior-related initiative on managing burnout symptoms should also be extended to university authorities in countries other than Nigeria for the remarkable emotional and psychological health benefits of their postgraduate students.

This finding may also be helpful to clinical and non-clinical professionals, administrators, and counselors who render dignified services to clients in managing burnout symptoms. It is also important that prospective researchers would further extend the scope of their investigations to find out alternative measures such as internet-based, of delivering similar interventions to the victims of burnout symptoms in different populations.

The study recorded some obvious limitation. For instance, this research was delimited to postgraduate students who were recruited from public universities in Nigeria. Therefore, the findings of the study were limited to this category of students. Further studies are recommended to investigate other groups of students (e.g.: undergraduates, and sandwich students) as well as individuals in other sectors of life on managing burnout symptoms using behavioral intervention.

\section{Conclusion}

This study showed that REBI was effective in managing burnout symptoms among postgraduate students in public universities in Nigeria. The outcome of the study is evidence-based as it unveils the impact of behavior-related interventions in managing emotional and psychological health problems such as burnout symptoms among students. Therefore, there is need for enlightenment and massive health education on burnout and prospective ways of managing it irrespective of socio-demographic differences. This could be achieved through well-organized workshops, group seminars and conferences specifically organized on burnout and other related emotional and psychological health problems.

\section{Acknowledgments}

None to declare

\section{Contributions by Authors}

UAE and EKN initiated the title and sourced for relevant literature. CCI and NEO wrote the manuscript, analyzed and interpreted the data. All the authors contributed to the study concept and design, acquisition of subjects and manuscript review. UCU drafted the manuscript and revising it critically for important intellectual content. All authors have read and approved the final version of the manuscript.

\section{Competing Interests Statement}

The authors declare that there are no competing or potential conflicts of interests.

\section{References}

Abarghouei, M. R., Sorbi, M. H., Abarghouei, M., Bidaki, R., \& Yazdanpoor, S. (2016). A study of job stress and burnout and related factors in the hospital personnel of Iran. Electronic physician, 8(7), 2625. https://doi.org/10.19082/2625

Al-Alawi, M., Al-Sinawi, H., Al-Qubtan, A., Al-Lawati, J., Al-Habsi, A., Al-Shuraiqi, M., ... \& Panchatcharam, S. M. (2019). Prevalence and determinants of burnout syndrome and depression among medical students at Sultan Qaboos University: a cross-sectional analytical study from Oman. Archives of environmental \& occupational health, 74(3), 130-139. https://doi.org/10.1080/19338244.2017.1400941 
dos Santos Boni, R. A., Paiva, C. E., De Oliveira, M. A., Lucchetti, G., Fregnani, J. H. T. G., \& Paiva, B. S. R. (2018). Burnout among medical students during the first years of undergraduate school: prevalence and associated factors. PloS one, 13(3). https://doi.org/10.1371/journal.pone.0191746

Campos, J. A., Carlotto, M. S., \& Marôco, J. (2012). Oldenburg Burnout Inventory student version: cultural adaptation and validation into Portuguese. Psicologia: Reflexão e Crítica, 25, 709-718. https://doi.org/10.1590/S0102-79722012000400010

Chou, L. P., Li, C. Y., \& Hu, S. C. (2014). Job stress and burnout in hospital employees: comparisons of different medical professions in a regional hospital in Taiwan. BMJ Open, 4, e004185. https://doi.org/10.1136/bmjopen-2013-004185

Dyrbye, L. N., West, C. P., Satele, D., Boone, S., Tan, L., Sloan, J., \& Shanafelt, T. D. (2014). Burnout among US medical students, residents, and early career physicians relative to the general US population. Academic Medicine, 89(3), 443-451. https://doi.org/10.1097/ACM.0000000000000134

Hamaideh, S. H. (2011). Stressors and reactions to stressors among university students. Int J Soc Psychiatry, 57, 69-80. https://doi.org/10.1177/0020764009348442

Heinen, I., Bullinger, M., \& Kocalevent, R. D. (2017). Perceived stress in first year medical students-associations with personal resources and emotional distress. BMC Med Educ., 17, 4. https://doi.org/10.1186/s12909-016-0841-8

Lin, S. H., \& Huang, Y. C. (2014). Life stress and academic burnout. Act Learn Higher Educ., 15, 77-90. https://doi.org/10.1177/1469787413514651

Ogbuanya, T. C., Eseadi, C., Orji, C. T., Omeje, J. C., Anyanwu, J. I., Ugwoke, S. C., \& Edeh, N. C. (2019). Effect of rational-emotive behavior therapy program on the symptoms of burnout syndrome among undergraduate electronics work students in Nigeria. Psychological reports, 122(1), 4-22. https://doi.org/10.1177/0033294117748587

Popa-Velea, O., Diaconescu, L., Mihăilescu, A., Jidveian Popescu, M., \& Macarie, G. (2017). Burnout and its relationships with alexithymia, stress, and social support among Romanian medical students: a cross-sectional study. International journal of environmental research and public health, 14(6), 560. https://doi.org/10.3390/ijerph14060560

Reis, D., Xanthopoulou, D., \& Tsaousis, I. (2015). Measuring job and academic burnout with the Oldenburg Burnout Inventory (OLBI): Factorial invariance across samples and countries. Burnout Res., 2, 8-18. https://doi.org/10.1016/j.burn.2014.11.001

Saghaei, M. (2014). Random Allocation Software [Computer Software]. Retrievedfromhttp://mahmoodsaghaei.tripod.com/Softwares/randalloc.html.

Sherin, J., \& Caiger, L. (2004). Rational-emotive behavior therapy: a behavioral change model for executive coaching? J Consult Clin Psychol., 6, 225-233. https://doi.org/10.1037/1065-9293.56.4.225

Tavolacci, M.P., \& Veber, B. (2015). Burnout and stress in medical students in France: prevalence and associated factors. Eur J Public Health, 25, 161-162. https://doi.org/10.1093/eurpub/ckv171.084

Ugwoke, S. C., Eseadi, C., Onuigbo, L. N., Aye, E. N., Akaneme, I. N., Oboegbulem, A. I., ... \& Ede, M. O. (2018). A rational-emotive stress management intervention for reducing job burnout and dysfunctional distress among special education teachers: an effect study. Medicine, 97(17). https://doi.org/10.1097/MD.0000000000010475

World Medical Association. (2013). Declaration of Helsinki Ethical Principles for Medical Research Involving Human Subjects. JAMA, 310, 2191-2194. https://doi.org/10.1001/jama.2013.281053

\section{Copyrights}

Copyright for this article is retained by the author(s), with first publication rights granted to the journal.

This is an open-access article distributed under the terms and conditions of the Creative Commons Attribution license (http://creativecommons.org/licenses/by/4.0/). 